\title{
Prevalence and Heritability of Early Childhood Caries Among Monozygotic and Dizygotic Twins
}

\author{
Anuradha Kuppan, ${ }^{1}$ Steven Rodrigues, ${ }^{1}$ Victor Samuel, ${ }^{2}$ Mahesh Ramakrishnan, ${ }^{1}$ Hassan S. Halawany, ${ }^{3,4}$ \\ Nimmi B. Abraham, ${ }^{4}$ Vimal Jacob, ${ }^{4}$ and Sukumaran Anil ${ }^{5}$ \\ ${ }^{1}$ Department of Pediatric Dentistry, Saveetha Dental College, Saveetha University, Chennai, India \\ ${ }^{2}$ Department of Pedodontics, Dental College, SRM University, Chennai, India \\ ${ }^{3}$ Department of Periodontics and Community Dentistry, College of Dentistry, King Saud University, Riyadh, Saudi Arabia \\ ${ }^{4}$ Dental Caries Research Chair, College of Dentistry, King Saud University, Riyadh, Saudi Arabia \\ ${ }^{5}$ Department of Preventive Dental Sciences, College of Dentistry, Prince Sattam Bin Abdulaziz University, Al-Kharj, Saudi \\ Arabia
}

\begin{abstract}
Deciphering the relative importance of genetic and environmental factors, which play a major role in the prevalence of early childhood caries (ECC), can help clinicians with planning a long-term preventive treatment. The objective of the study was to determine the prevalence and heritability of ECC among monozygotic (MZ) and dizygotic (DZ) twins in Chennai, India, in the year 2013. A cross-sectional study was designed to estimate the prevalence of ECC among twins. Zygosity classification for the survey framework was adapted from a highly accurate parental report questionnaire pertaining to the physical similarity between twins. The associated heritability index was estimated. The Decayed, Missing, Filled Surface (DMFS) Index was used as the diagnostic criterion for dental caries. The prevalence of ECC was estimated at $18.7 \%$. The correlation coefficient between the twin pair showed significant correlation. The heritability index for ECC was estimated at $15 \%$ higher prevalence of ECC found among children in the age group 25-36 months. The heritability estimate indicated a relatively low genetic influence for early childhood caries among twins. There was no significant difference detected in the concordance rate for the MZ and DZ twins. Further research could be directed toward the prevalence of ECC among higher age group children to explore the role of genetic and environmental factors.
\end{abstract}

Keywords: twins, dental caries, early childhood caries, heritability, dizygotic, monozygotic, genetic factors

The manifestation of dental caries is a complex mechanism triggered by genetic, behavioral, environmental, and microbial factors (Corby et al., 2005). Genetic research applied to dental decay began in the 1930s with experimental reports in animal models and observational research applied to human populations (Werneck et al., 2010). One of the most direct methods for analyzing the contribution of inheritance to disease is the study of genetics in twins (Shuler, 2001). Although twin studies have been used to estimate the influence of genetic factors on the etiology of dental caries, few available studies emphasize genetics as a significant contributor (Bretz et al., 2003). In earlier twin studies, there were wide variations in the designs, populations, caries scoring, and zygosity determination methods used. Moreover, prenatal biases, co-habitational effects, sample selection, and methodological factors may all confound the results of such studies (Conry et al., 1993).

Twins can be either monozygotic (MZ) identical twins, who share $100 \%$ of their genetic variants, or dizygotic (DZ) non-identical twins, who share $50 \%$ of their genetic variants. The classic twin design is to compare the resemblance between MZ and DZ twins for a trait. For MZ twins, who are more similar in their genetic aspect and are brought up in the same environment, any difference indicates a strong genetic effect (Hassell \& Harris, 1995). The first study to evaluate the caries incidence in twins was conducted in 1927, and it concluded that heredity plays a subsidiary part in the incidence of caries (Bachrach \& Young, 1927). Later, it was suggested that MZ twins had a greater concordance than either DZ twins or unrelated controls (Shuler, 2001). A study conducted by Bretz et al. (2005)

RECEIVED 10 May 2016; ACCEPTED 10 November 2016

ADDRess For CORRESPONDENCE: Dr. Sukumaran Anil, Department of Preventive Dental Sciences, College of Dentistry, Prince Sattam Bin Abdulaziz University, Post Box 153, AI-Kharj 11942, Saudi Arabia. E-mail: drsanil@gmail.com 
concluded that heritability estimates were greatest at the age of 1.5 years, decreased at 4 years, and increased at 6 years. However, most of these studies were carried out in twins with a wide age range.

The Center for Disease Control and Prevention labeled caries in primary teeth as early childhood caries (ECC) at a workshop held in 1994 (Tinanoff, 1998). The American Academy of Pediatric Dentistry defined ECC as the presence of caries (cavitated or non-cavitated) in one or more primary teeth in a child 71 months of age or younger (American Academy of Pediatric Dentistry, 2014). A literature review of the epidemiology of ECC showed that the prevalence of ECC varies among populations, but disadvantaged children are more susceptible to caries regardless of race, ethnicity or culture (Milnes, 1996). In infants and children in high-risk groups, the prevalence of ECC is estimated to range from $1 \%$ to $12 \%$ (Burt \& Eklund, 2005) and from $50 \%$ to $80 \%$, respectively (Hallett \& O'Rourke, 2003). Various prevalence studies on ECC have been performed in India. Prakash et al. (2012) reported a prevalence of $27.5 \%$, whereas Retnakumari and Cyriac (2012) reported it as $50.6 \%$. ECC is epidemic, and the severity of the problem appears to be distinct for varying cultures, genetic profiles, and socio-economic statuses within a community (Kumarihamy et al., 2011).

Most studies of the genetic tendency toward dental caries have been based on older age groups and moderate sample sizes. To the best of our knowledge, no study has reported the prevalence of ECC among twins. Therefore, our aim was to determine the prevalence and heritability of ECC among $\mathrm{MZ}$ and DZ twin pairs as a baseline study to conceptualize the possible role of genetics in ECC. The findings from this study will complement the relative dearth of literature concerning ECC among twin pairs.

\section{Materials and Methods}

This cross-sectional study was conducted among twin pairs in Chennai, the capital city of Tamil Nadu, India, to assess the possible genetic contribution to ECC. Chennai is the fourth most populous metropolitan city in India, with an estimated population of 4.59 million as of 2009 . Chennai is divided into 15 zones according to the state council. Ethical clearance for the study was obtained from the Institutional Review Board of Saveetha University, Chennai, India.

\section{Subject Selection and Sampling Procedure}

This survey was conducted from May to July 2013. The twins' database from the year 2010-2012 was accessed through the Chennai Corporation, a government-run organization that registers vital events in the city. The population census of Tamil Nadu and its capital Chennai were obtained from the website of the Department of Health and Family Welfare, Government of Tamil Nadu (Health and Family Welfare Department, 2013). The crude birth rate as per the Census of India (2009-2011) was 15.5\%, with an infant mortality rate of $21 \%$ (Census Organization of India, 2011). During the period of 2010-2012, among a total of 232,884 births registered in the city of Chennai, 4,500 were twin births (i.e., 19.3 per 1,000 deliveries); among these, 1,371 pairs were residing in Chennai at the time of study. The subjects were divided according to their addresses and segregated into their respective city corporation zone. The anticipated population proportion was calculated and estimated on the presumption of an early childhood caries prevalence of $25 \%$, with a desired precision of $\pm 10 \%$ and a confidence level of $95 \%$. A multistage sampling design using a probability proportion scheme (PPS) was employed to select a sample of the twins from each zone. The study was conducted zone-wise, and the addresses in each zone were randomly selected using randomizer software (RANDOM.ORG ${ }^{\odot}$ 1998-2014). Our planned sample size was approximately 10 twin pairs per zone (300 in total) selected from the 1,371 pairs from the 9 zones (zones $4-10,12$, and 13) of Chennai Corporation. Figures 1 and 2 show the distribution of twins in the various zones in Chennai that were selected for this study. Zones 4 and 5 had the maximum number of twin pairs compared with the other zones.

\section{Pilot Study and Examiner Calibration}

Before the main study began, the survey protocol was pilot tested with 10 twin pairs aged from 6 months to 6 years, randomly selected from Ambattur zone number 7 , to determine the feasibility of this study and the amount of time required to collect the questionnaire and orally examine each subject, based on the WHO criteria. As a single examiner carried out the examination, intra-examiner calibration was performed. Zygosity determination and oral examinations were performed for 20 subjects who were re-examined 3 weeks later. Reproducibility was assessed using the kappa value, which was 0.82 .

\section{Inclusion and Exclusion Criteria}

Based on the feedback obtained from pilot study, the age in the main study was reduced, as we assumed that most of the hereditary effects could be evaluated only in a younger age group and that after 4 years of age, environmental factors would have a greater influence. Thus, the inclusion criteria for the study were twins residing in Chennai aged from 6 months to 3 years with at least one erupted tooth. The exclusion criteria were individuals who were medically compromised and whose parents did not give consent for participation.

\section{Address Verification}

The addresses were physically verified, and if the subjects were still residing at the address provided to the Corporation, they were selected for the study. The parents or subjects were revisited on many occasions at their homes to 


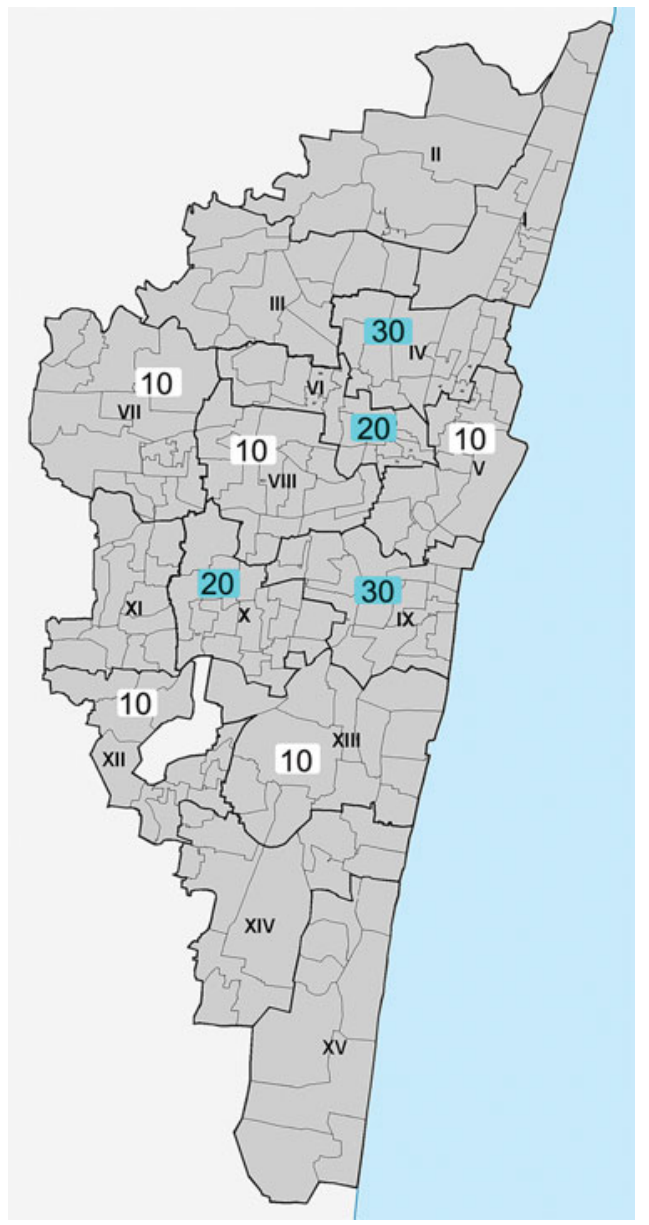

\section{FIGURE 1}

(Colour online) The distribution of twins in the various zones that were selected in Chennai. Zones 4 and 5 had the maximum number of twin pairs compared with those in the other zones.

establish their consent for a later time. If the address was found to be incorrect or non-existent, or if the family had moved to a different address, the subject was excluded from the study, and a new subject was selected using the randomization technique. The same was done for subjects whose parents were not willing to take part in the study.

\section{Informed Consent}

Parents were given a short oral health education session with appropriate aids and they were also informed about the aim of the study, its benefit to the subject, and society in general. Their queries regarding the same were answered. After a signed informed consent was obtained from a parent or carer of the twins, the study was commenced, which included a questionnaire for the parent and oral examination of the twins. They were provided with a pamphlet about awareness of ECC at the end of the survey.

\section{Questionnaire for Zygosity Determination}

Zygosity classification for the survey framework was adapted from a highly accurate parental report questionnaire pertaining to the physical similarity between the twins. This questionnaire was derived from a previous study in which the authors had validated the questionnaire against zygosity determined by the identity of polymorphic DNA markers (Price et al., 2000). The questionnaire consisted of 18 items. The items were scored numerically, with low scores given to responses indicating similarity between twins and high scores given to responses indicating dissimilarity. These scores were summed and then divided by the maximum score possible on the questions that were answered to create a physical similarity quotient (PSQ) ranging from zero (representing maximal physical similarity) and one (representing maximum physical dissimilarity).

\section{Oral Examination}

All of the children were examined at their respective houses with a flashlight, disposable mouth mirrors, and explorers. The children were placed in a supine position, and for very young children, the knee-to-knee method was employed. A caretaker or parent was also present with the subject to help the examiner with behavior management. The oral examination was conducted by one dentist after a 1-week training program for identifying cavitated and non-cavitated lesions. The dentist recorded data related to the presence of decayed, missing, and filled surfaces (DMFS). The findings of the intra-oral examination were recorded according to WHO criteria for caries and reported to the parents after the survey. Children who required complex treatment were referred to Saveetha Dental College and Hospital for further management.

\section{Statistical Analysis}

The survey data were managed using the Statistical Package for Social Sciences software (SPSS Version 20, SPSS, Inc., Chicago, IL, USA) for the purpose of data analysis. Descriptive statistics, including frequencies and percentages for categorical variables and means and standard deviations $(S D)$ for continuous variables, were calculated. The caries status and caries prevalence were combined for the twins to calculate the correlation and the heritability index. We considered $p$ values $<.05$ statistically significant.

\section{Results}

In this study, 158 families with twins were approached in Chennai City and 150 families successfully completed the survey. Eight families were unable to participate because of travel plans, schedule conflicts or the illness of a family member. The mean age of the twins was $24.7 \pm 7.4$ months.

Twin pairs with a PSQ $\geq 0.50$ were assigned to the $\mathrm{DZ}$ group, and those with a PSQ $\leq 0.49$ were assigned to the MZ 


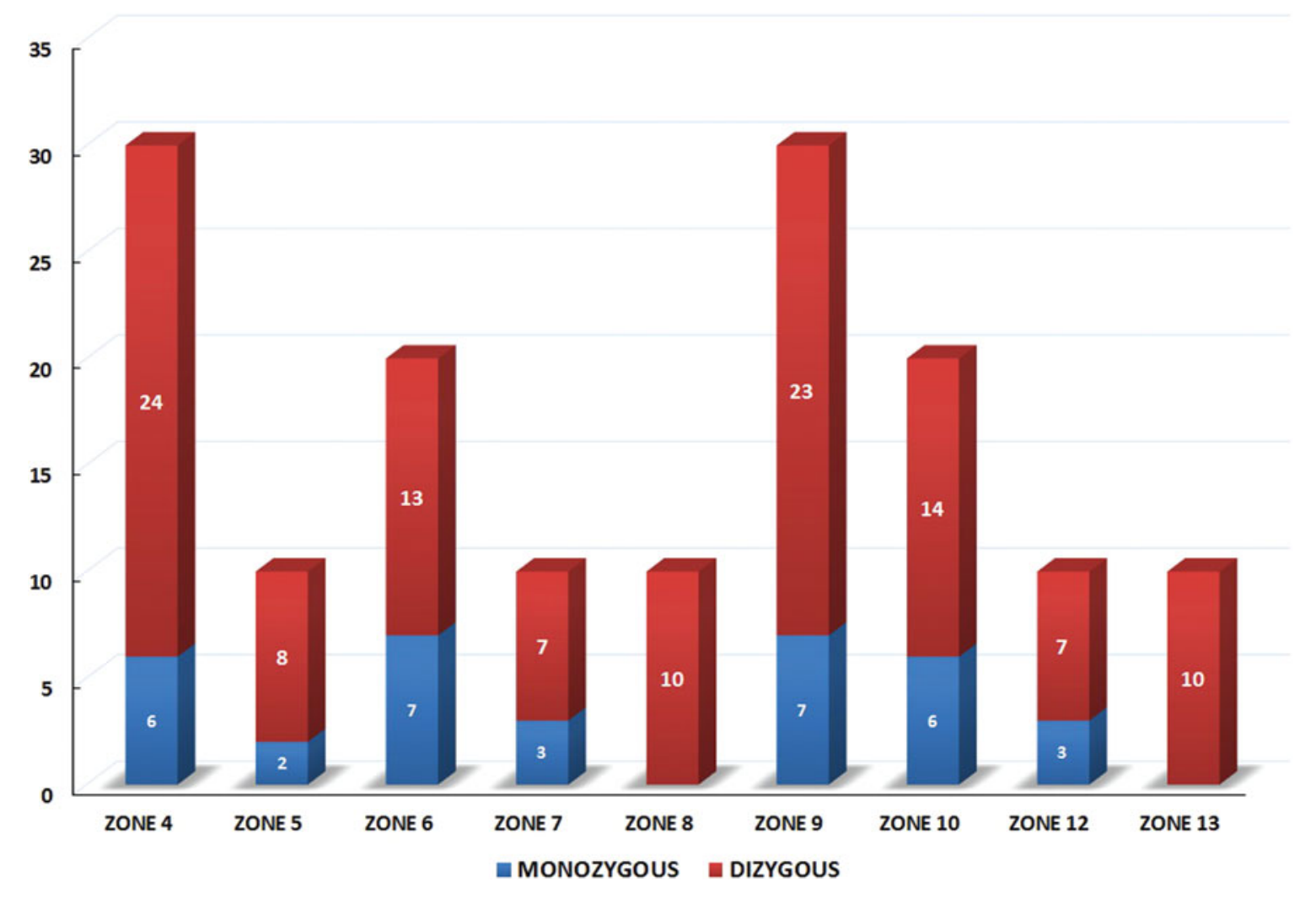

\section{FIGURE 2}

(Colour online) The distribution of MZ and DZ twins in various zones.

group. In the MZ group, the mean PSQ was $0.34 \pm 0.04$, and in the DZ group the PSQ value was $0.74 \pm 0.08$ (Figure 3 ).

The frequency distribution and the percentage value of DMFS in relation to zygosity and age group are presented in Table 1. The prevalence of ECC of 150 pairs of twin children aged 6 months to 3 years was $18.7 \%$ and mean DMFS was 1.32. There was a higher prevalence of ECC among children older than 2 years. Figure 4 depicts the zone-wise distribution of DMFS. Children with caries were more prevalent in zones 4 and 9 compared with the other zones. There were no children with caries in zone 7.

Table 2 shows the significance of DMFS and zygosity values. The concordance percentage for MZ twins was $91.2 \%$ and for DZ twins it was $92.2 \%$. The discordance percentage for $\mathrm{MZ}$ twins was $8.8 \%$ and for $\mathrm{DZ}$ twins it was $7.8 \%$, giving a $p$ value of .840 , which is not significant between the two groups.

The heritability estimates of disease risk or a quantitative trait was detected by comparing the variance among the twins. An estimate of heritability (h2) was derived according to the formula: $h^{2}=2\left(r_{\mathrm{mz}}-r_{\mathrm{dz}}\right)$, where $r_{\mathrm{mz}}$ and $r_{\mathrm{dz}}$ are the values of the correlation coefficients between samples of MZ and DZ twins (Holzinger, 1929). Table 3 shows the correlation of DMFS between MZ and DZ twins. The correlation is more significant between the MZ twins (0.657), $p$ value $<.001$, than the $\mathrm{DZ}$ twins (.592). The heritability in- dex showing the correlation between $\mathrm{MZ}$ and $\mathrm{DZ}$ twins was $15 \%$.

The influence of various factors in $\mathrm{MZ}$ and $\mathrm{DZ}$ twins with and without ECC is shown in Table 4. The mean gestational age of the cohort was $36 \pm 2.1$ weeks, with $186(62 \%)$ children born pre-term (<37 weeks gestation), 114 (38\%) born term, and the majority delivered via cesarean section (91\%). The tooth brushing by a parent and a combination of breastfeeding and bottle feeding were practiced by a significant majority of the DZ twins compared with the MZ twins ( $p=.028$ and $p<.001$, respectively). Snacking less than two times per day $(p<.001)$ and a lack of night-time feeding $(p=.025)$ were significantly associated with a reduced prevalence of ECC. However, in our sample, a majority of the caries-free children also engaged in night-time feeding. The majority of the twins' mothers had a college or university education, and there was a significantly higher number of highly educated mothers among the DZ group compared with the MZ group $(p=.012)$. In contrast, ECC awareness was lower among the parents of the twins $(p=.033)$.

\section{Discussion}

To the authors' knowledge, this is the first prevalence study on the primary dentition of twins in the Indian population. The classical twin study design involving MZ twins and 


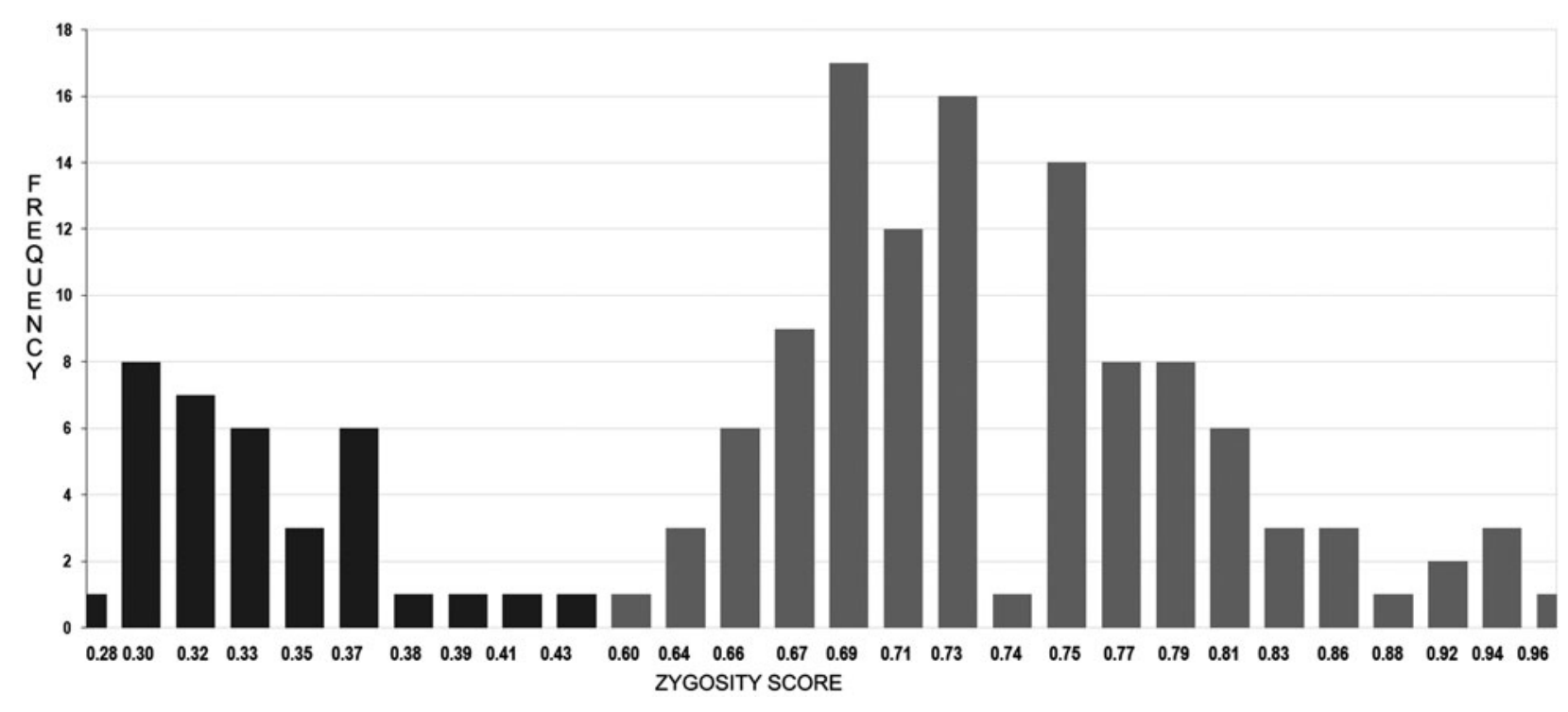

FIGURE 3

The PSQ values of 150 twin pairs, the total number of MZ twins was $34(22.7 \%)$, and the total number of DZ twins was $116(77.3 \%)$, for a ratio of $1: 3$.

\section{TABLE 1}

The Number and Percentage of DMFS in Relation to Zygosity and Age Group

\begin{tabular}{|c|c|c|c|c|c|c|c|c|}
\hline \multirow[b]{3}{*}{ Age group } & \multicolumn{8}{|c|}{ Decayed, missing, and filled surfaces (DMFS) } \\
\hline & \multicolumn{2}{|c|}{ 6-12 months } & \multicolumn{2}{|c|}{$13-24$ months } & \multicolumn{2}{|c|}{$25-36$ months } & \multicolumn{2}{|c|}{ Total } \\
\hline & $n$ & $\%$ & $n$ & $\%$ & $n$ & $\%$ & $N$ & $\%$ \\
\hline Monozygotic $(n=34)$ & 0 & 0 & 1 & 7.1 & 6 & 33.3 & 7 & 20.6 \\
\hline Dizygotic $(n=116)$ & 1 & 11.1 & 6 & 11.5 & 14 & 25.5 & 21 & 18.1 \\
\hline Total $(n=150)$ & 1 & 9.1 & 7 & 10.6 & 20 & 27.4 & 28 & 18.7 \\
\hline
\end{tabular}

TABLE 2

Significance of DMFS and Zygosity Values

\begin{tabular}{|c|c|c|c|c|c|c|}
\hline \multirow[b]{3}{*}{ Zygosity } & \multicolumn{6}{|c|}{ DMFS significance } \\
\hline & \multicolumn{2}{|c|}{ Concordance } & \multicolumn{2}{|c|}{ Discordance } & \multicolumn{2}{|c|}{ Total } \\
\hline & $n$ & $\%$ & $n$ & $\%$ & $N$ & $\%$ \\
\hline Monozygotic & 31 & 91.2 & 3 & 8.8 & 34 & 100 \\
\hline Dizygotic & 107 & 92.2 & 9 & 7.8 & 116 & 100 \\
\hline Total & 138 & 92 & 12 & 8 & 150 & 100 \\
\hline
\end{tabular}

TABLE 3

Correlations of DMFS Between Twins

\begin{tabular}{lcll}
\hline Zygosity & $n$ & Correlation & $p$ value \\
\hline Monozygotic & 34 & 0.657 & $<.001$ \\
Dizygotic & 116 & 0.592 & $<.001$ \\
Overall & 150 & 0.59 & $<.001$ \\
\hline
\end{tabular}

DZ twins quantifies the relative contribution of genetic (nature) and environmental (nurture) factors (Townsend et al., 1998). MZ twins develop from a single fertilized ovum and proceed to divide into two individuals, whereas DZ twins develop from two different ova and develop into two indi- viduals. Therefore, MZ twins are identical and of the same sex, whereas DZ twins are non-identical, and approximately half are male-female pairs (Gittelsohn \& Milham, 1965).

In twin studies, the positive ascertainment of zygosity is of extreme importance (Hassell \& Harris, 1995). When the zygosity determination is incorrect, it can potentially have an enormous effect on heritability estimates (Jackson et al., 2001). There are various methods for ascertaining zygosity, such as serological systems, dermatoglyphic findings, and questionnaires. In serological systems, immunologic typing of blood antigens is conducted, and any discrepancies between a twin pair denotes that the twins are DZ (Lykken, 1978), providing accurate zygosity determination (98-99\%; Costanzi Porrini et al., 1990). An accuracy of $97-98 \%$ is seen in serological systems for classifying the zygosity of twins (Lykken, 1978; Wilson, 1980). Dermatoglyphic findings have a comparatively lower accuracy rate (Slater, 1963). For large-scale studies, biological assessments are not always feasible (Ooki et al., 1993; Peeters et al., 1998). Therefore, physical similarity questionnaires for zygosity classification were developed by Goldsmith (1991). Many authors have modified Goldsmith's questionnaire and have reported an accuracy rate of 93\% (Chen et al., 1999; Price et al., 2000; 


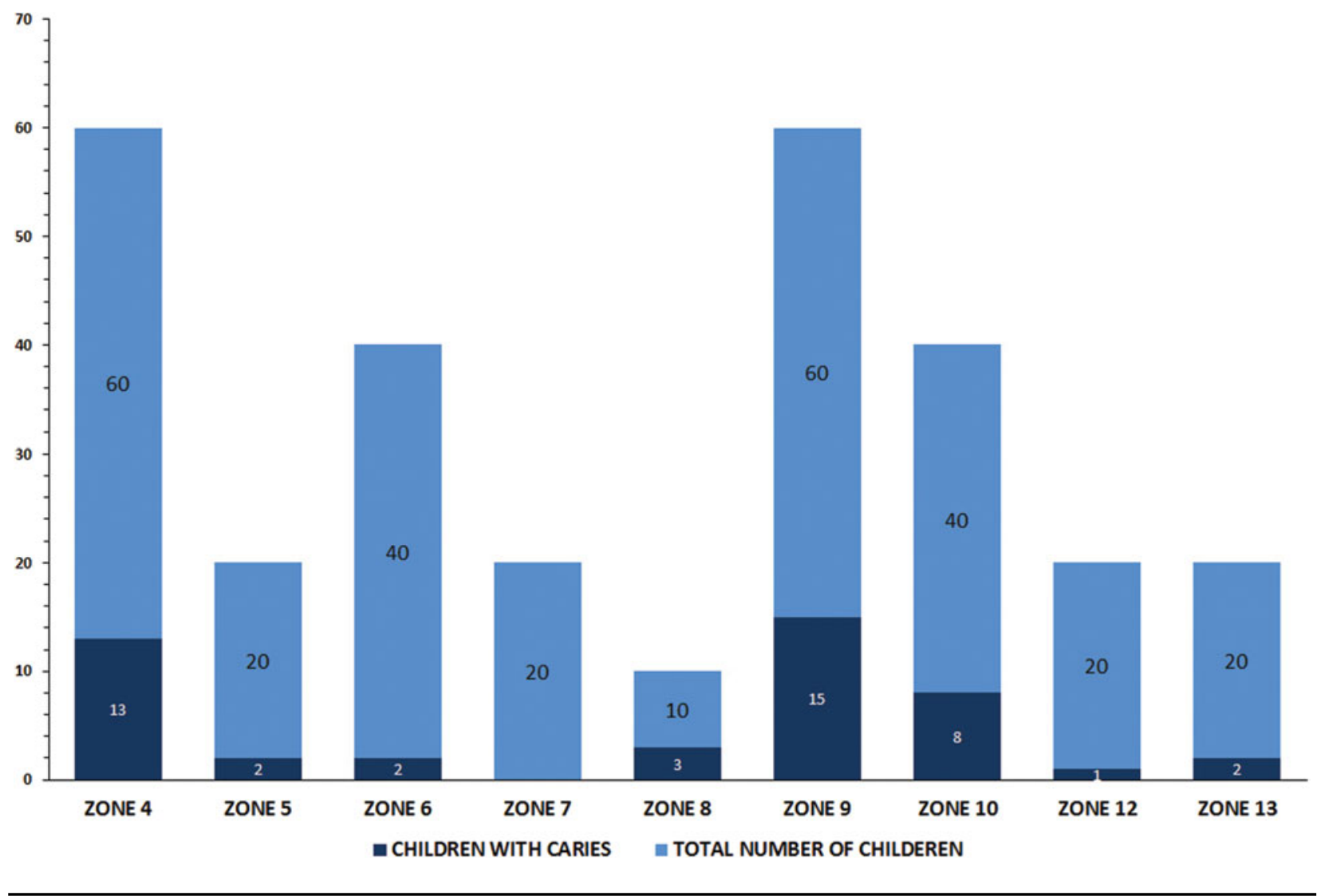

FIGURE 4

(Colour online) The DMFS distribution based on the zones. Children with caries were more prevalent in zones 4 and 9 compared with those in the other zones. There were no children with caries in zone 7.

Spitz et al., 1996). The agreement between serological markers and questionnaires ranges between $93 \%$ and $95 \%$ (Jackson et al., 2001). In large-scale studies, the questionnaire method of zygosity determination has been widely used (Hassell \& Harris, 1995). In this study, zygosity was determined according to a very accurate validated questionnaire method proposed by Price et al. (2000). There were a total of 18 reliable questions with which the physical similarity quotient (PSQ) was calculated. The prevalence rate of $\mathrm{MZ}$ and DZ twins in this study was 1:3, which is in accordance with previously published literature (Sharma, 1997). Carroll et al. (2005) reported an MZ-to-DZ ratio of 1:2. It was evident that zones 4 and 9 (Tondairpet and Teyanampet, respectively) in Chennai had the maximum number of twin pairs.

ECC continues to pose a serious threat to child welfare, despite improvements in the oral health of children in recent decades. It is important to know the prevalence of ECC to assess the burden of the disease in a population to provide better health services. Many studies have been conducted in India to determine the prevalence of ECC. Prakash et al. (2012) reported a prevalence rate of $27.5 \%$ in 1,500 children in Bangalore, Karnataka, and the highest prevalence of $68.7 \%$ was reported by Kalra et al. (2011) among 600 children in Haryana. There have been no reports on the prevalence of caries among twins in India. In this study, the overall prevalence among 150 pairs of twins was $18.7 \%$. ECC prevalence seemed to be higher among the children older than 2 years in both the MZ and DZ pairs. This is in line with the earlier reports that ECC is more prevalent in older children aged between 3 and 6 years (Gopal et al., 2016; Moimaz et al., 2016; Wang et al., 2010). Wang et al (2010) studied the genes and their effects on dental caries in primary and permanent dentitions. They found that caries scores were moderately to highly heritable, and that different genes might be responsible for the variation in primary and permanent dentition.

Heredity has been linked with dental caries, and earlier reports revealed that genetics plays a substantial role, with heritability ranging from $40 \%$ to $60 \%$ (Hassell \& Harris, 1995; Wang et al., 2010; Werneck et al., 2010). One of the largest genome-wide association studies of dental caries showed a plausible genetic influence in the etiology of dental caries (Morrison et al., 2016). The analysis of two common polymorphisms in the sweet taste receptor(TAS1R2) and glucose transporter (GLUT2) genes in children with dental caries revealed a possible influence of specific genetic variants in the GLUT2 and TAS1R2 genes on caries 
TABLE 4

The Influence of Various Factors in Monozygotic and Dizygotic Twins With and Without ECC

\begin{tabular}{|c|c|c|c|c|c|c|}
\hline Variables & $\begin{array}{l}\text { MZ twins } \\
(n=64) \\
n(\%)\end{array}$ & $\begin{array}{l}\text { DZ twins } \\
(n=236) \\
n(\%)\end{array}$ & $\begin{array}{l}\text { p value } \\
\text { (MZ vs. DZ) }\end{array}$ & $\begin{array}{l}\text { Children with } \\
\text { ECC }(n=45) \\
n(\%)\end{array}$ & $\begin{array}{l}\text { Children without } \\
\text { ECC }(n=257) \\
n(\%)\end{array}$ & $p$ value \\
\hline \multicolumn{7}{|l|}{ Age of the child } \\
\hline$\leq 2$ years & $29(45)$ & $126(53)$ & \multirow[t]{2}{*}{ NS } & $9(20)$ & $146(57)$ & \multirow[t]{2}{*}{$<.001^{* *}$} \\
\hline$>2$ years & $35(55)$ & $110(47)$ & & $34(76)$ & $111(43)$ & \\
\hline \multicolumn{7}{|l|}{ Parent/caregiver brushes child's teeth } \\
\hline Yes/sometimes & $41(64)$ & $183(78)$ & \multirow[t]{2}{*}{$.028^{*}$} & $34(76)$ & $190(74)$ & \multirow[t]{2}{*}{ NS } \\
\hline No & $23(36)$ & $53(23)$ & & $9(20)$ & $67(26)$ & \\
\hline \multicolumn{7}{|l|}{ Feeding practices } \\
\hline Breastfed & $16(25)$ & $22(9)$ & \multirow[t]{3}{*}{$<.001^{*}$} & $2(4)$ & $36(14)$ & \multirow[t]{3}{*}{ NS } \\
\hline Bottle fed & $4(6)$ & $7(3)$ & & $2(4)$ & $9(4)$ & \\
\hline Combination (breastfed+ bottle fed) & $38(59)$ & $206(87)$ & & $37(82)$ & $207(81)$ & \\
\hline \multicolumn{7}{|l|}{ Snacking per day } \\
\hline$\leq 2$ times per day & $58(91)$ & 219 (93) & \multirow[t]{2}{*}{ NS } & $33(73)$ & $244(95)$ & \multirow[t]{2}{*}{$<.001^{* *}$} \\
\hline$>2$ times per day & $6(9)$ & $16(7)$ & & $10(22)$ & $12(5)$ & \\
\hline \multicolumn{7}{|l|}{ Night-time feeding } \\
\hline Yes & $46(72)$ & $168(71)$ & \multirow[t]{2}{*}{ NS } & $25(56)$ & $189(74)$ & \multirow[t]{2}{*}{$.025^{*}$} \\
\hline No & $14(22)$ & $68(29)$ & & $18(40)$ & $64(25)$ & \\
\hline \multicolumn{7}{|l|}{ Mother's educational level } \\
\hline Illiterate & $4(6)$ & $4(2)$ & \multirow[t]{4}{*}{$.012^{*}$} & $0(0.0)$ & $8(3)$ & \multirow[t]{4}{*}{ NS } \\
\hline Less than high school & $18(28)$ & $44(19)$ & & $9(20)$ & $53(21)$ & \\
\hline High school & $16(25)$ & 40 (17) & & $10(22)$ & $46(18)$ & \\
\hline College/university completed & $26(41)$ & $138(59)$ & & $23(51)$ & $141(55)$ & \\
\hline \multicolumn{7}{|l|}{ Mother's work status } \\
\hline Housewife & $52(81)$ & $204(86)$ & \multirow[t]{3}{*}{ NS } & $37(82)$ & $219(85)$ & \multirow[t]{3}{*}{ NS } \\
\hline Working part time & $6(9)$ & $12(5)$ & & $2(4)$ & $16(6)$ & \\
\hline Working full time & $4(6)$ & $14(6)$ & & $4(9)$ & $14(5)$ & \\
\hline \multicolumn{7}{|l|}{ Parent's awareness of ECC } \\
\hline Yes & $10(16)$ & $68(29)$ & \multirow[t]{2}{*}{$.033^{*}$} & $14(31)$ & $64(25)$ & \multirow[t]{2}{*}{ NS } \\
\hline No & $54(84)$ & $168(71)$ & & $29(64)$ & $193(75)$ & \\
\hline
\end{tabular}

Note: $\mathrm{DZ}=$ dizygotic; $\mathrm{MZ}=$ monozygotic; DMFS = decayed, missing and filled surfaces; NS = not significant. There were no filled teeth and only one missing tooth due to caries in the DZ group, there were missing values for mother's educational level and work status. ${ }^{*} p$ value < 05 .

${ }^{\star \star} p$ value $<.001$ statistically significant.

risk (Izakovicova Holla et al., 2015). Zhang et al. (2015) analyzed the plaque microflora in twin children with discordant caries phenotypes and found that the microbial composition observed in twins was usually similar. They concluded that genetic factors primarily influence the individual's susceptibility to dental caries and that environmental factors primarily regulate the microbial composition of the dental plaque and the progression to caries.

Twin studies on dental caries have shown that genetic as well as environmental factors play a significant role (Bretz et al., 2005; Conry et al., 1993; Lovelina et al., 2012; Mansbridge, 1959). The susceptibility or resistance to caries could be a result of one or more genotypic, phenotypic, and environmental influences (Opal et al., 2015). Heritability estimates refer to the proportion of variation in a phenotype at a given point of time that may be attributed to genetic differences between individuals (Lee et al., 2011). Mansbridge (1959) studied the caries incidence in $96 \mathrm{MZ}$ and $128 \mathrm{DZ}$ twins. The study showed that dental caries experience had a greater similarity between MZ twins than DZ twins, whereas unrelated pairs of children showed less similarity. This observation was supported by other studies that showed dental caries resemblance was higher among MZ twins (Conry et al., 1993; Lovelina et al., 2012). The MZ twins showed a greater correlation than the DZ twins, which is in accordance with these studies. Liu et al. (1998) studied various dental traits in 82 pairs of twins aged 612 years. Caries occurrence showed significant differences between the $\mathrm{MZ}$ and $\mathrm{DZ}$ groups, and the heritability was $24.47 \%$. Bretz et al. (2005) studied the caries pattern in 314 twin pairs between 1.5 years and 8 years of age and found that the heritability estimates were greatest at 1.5 years of age. Furthermore, Ooi et al. (2014) studied the prevalence of caries in 84 twins between 4 and 6 years of age and found that $18 \%$ of the DZ twin pairs had caries, compared with $3 \%$ of the MZ twins. A study by Gao (1990) from China reported dental caries heritability index of $8.7 \%$ in 280 pairs of same-sex twins (186 MZ and $94 \mathrm{DZ}$ ). In our study, the ECC heritability estimate was $15 \%$, which is in accordance with some of these reports, indicating a relatively lower genetic influence than the environmental factors (Gao, 1990; Ooi et al., 2014).

The genetic susceptibility pattern also exhibited a surface hierarchy to decay, with pit and fissure surfaces exhibiting much greater risk than smooth surfaces (Batchelor \& Sheiham, 2004; Psoter et al., 2009; Shaffer et al., 2012; Zeng et al., 2013). Shaffer et al. (2012) noted that the heritability of caries scores for both pit and fissure and smooth surface in primary dentition was greater than in the permanent dentition and total dentition. They concluded that genetic factors 
may exert differential effects on caries risk in pit and fissure surfaces and smooth surface in the primary dentition. In a study of 314 twins, Bretz et al. (2005) found a significantly high heritability score for surface caries.

Although oral hygiene habits have been found to be essential for periodontal health and the prevention of caries, the most important factor is reducing the frequency of sugar consumption (Ainamo, 1980). Parents' regular brushing of their child's teeth illustrated the family members' competency in general terms, their ability and interest in caring for their child's oral health in particular, and their ability to limit the use of sugar and sweets (Paunio et al., 1993). Kalsbeek and Verrips (1994) showed a positive connection between the consumption of sweets and snacks and the rate of caries occurrence. This supports the findings of the present study regarding eating snacks more than two times per day and night-time feeding practices; these factors had significant associations with the prevalence of ECC in our sample of young children.

Our study has certain limitations that may have influenced the ability to extrapolate our results extensively. The major limitation of the study was the use of a questionnaire to determine the zygosity of the twins. Although the results of the questionnaire method for determining zygosity are 93-95\% consistent with the results of serological marker tests, there may be reliability issues (Cutler et al., 2015; Price et al., 2000). Additionally, our data cannot be generalized as this study was conducted with an Indian population. We further acknowledge that the heritability estimates cannot be directly linked to complex, multifactorial conditions such as dental caries because of various associated confounding factors. Because of the incongruent methodologies used in previous twin studies, it was somewhat problematic to compare our study of heritability for ECC among young children; hence, some of our findings may be underestimated. Additionally, the sample size of twins included in the study analysis meant that the investigation had a slightly weak statistical power. Because there have been no previous reports concerning ECC among twins in the Indian population, we have no information about the sampling bias based on geographic area for comparison. The observations of the present study revealed relatively low heritability of ECC in MZ and DZ twins. This further emphasizes the role of genetic and environmental factors in the etiology of dental caries.

\section{Acknowledgments}

The authors are very thankful to all the twins and their families who agreed to participate in our study, which was approved by the Human Research Ethics Committee at Saveetha University, and to all the staff members for their constant support throughout this study. We also wish to acknowledge that this research was made possible by the
Chennai Corporation Officer Dr G. T. Thangaraj, who allowed us access to the Twin Registry of Chennai.

\section{References}

Ainamo, J. (1980). Relative roles of toothbrushing, sucrose consumption and fluorides in the maintenance of oral health in children. International Dental Journal, 30, 54-66.

American Academy of Pediatric Dentistry. (2014). Policy on early childhood caries (ECC): Classifications, consequences, and preventive strategies. Pediatric Dentistry, 37, 50-52.

Bachrach, F. H., \& Young, M. (1927). A comparison of the degree of resemblance in dental characters shown in pairs of twins of identical and fraternal types. British Dental Journal, 48, 1293-1304.

Batchelor, P. A., \& Sheiham, A. (2004). Grouping of tooth surfaces by susceptibility to caries: A study in 5-16 year-old children. BMC Oral Health, 4, 2.

Bretz, W. A., Corby, P., Schork, N., \& Hart, T. C. (2003). Evidence of a contribution of genetic factors to dental caries risk. The Journal of Evidence-Based Dental Practice, 3, 185189.

Bretz, W. A., Corby, P. M., Schork, N. J., Robinson, M. T., Coelho, M., Costa, S., ... Hart, T. C. (2005). Longitudinal analysis of heritability for dental caries traits. Journal of Dental Research, 84, 1047-1051.

Burt, B. A., \& Eklund, S. A. (2005). Dentistry, dental practice, and the community. St Louis, MO: Elsevier Health Sciences.

Carroll, S. G., Tyfield, L., Reeve, L., Porter, H., Soothill, P., \& Kyle, P. M. (2005). Is zygosity or chorionicity the main determinant of fetal outcome in twin pregnancies? American Journal of Obstetrics and Gynecology, 193, 757-761.

Census Organization of India (2011). Figures at a glance, India - 2011. Retrieved from http://www.censusindia.gov. in/vital_statistics/SRS_Report/2At $\% 20 a \% 20$ glance $\% 20 \%$ 202011.pdf

Chen, W. J., Chang, H. W., Wu, M. Z., Lin, C. C., Chang, C., Chiu, Y. N., \& Soong, W. T. (1999). Diagnosis of zygosity by questionnaire and polymarker polymerase chain reaction in young twins. Behavior Genetics, 29, 115-123.

Conry, J. P., Messer, L. B., Boraas, J. C., Aeppli, D. P., \& Bouchard, T. J., Jr. (1993). Dental caries and treatment characteristics in human twins reared apart. Archives of Oral Biology, 38, 937-943.

Corby, P. M., Lyons-Weiler, J., Bretz, W. A., Hart, T. C., Aas, J. A., Boumenna, T., ... Paster, B. J. (2005). Microbial risk indicators of early childhood caries. Journal of Clinical Microbiology, 43, 5753-5759.

Costanzi Porrini, S., Sciarra, A., Sulli, N., Piane, M., Gualtieri, R., \& Del Porto, G. (1990). Variable number of tandem repeats in zygosity diagnosis in twins. Acta Geneticae Medicae et Gemellologiae, 39, 473-477.

Cutler, T. L., Murphy, K., Hopper, J. L., Keogh, L. A., Dai, Y., \& Craig, J. M. (2015). Why accurate knowledge of zygosity is important to twins. Twin Research and Human Genetics, $18,298-305$. 
Gao, X. J. (1990). [Dental caries in 280 pairs of same-sex twins]. Zhonghua Kou Qiang Yi Xue Za Zhi, 25, 18-20, 61.

Gittelsohn, A. M., \& Milham, S., Jr. (1965). Observations on twinning in New York State. British Journal of Preventive and Social Medicine, 19, 8-17.

Goldsmith, H. H. (1991). A zygosity questionnaire for young twins: A research note. Behavior Genetics, 21, 257-269.

Gopal, S., Chandrappa, V., Kadidal, U., Rayala, C., \& Vegesna, M. (2016). Prevalence and predictors of early childhood caries in 3- to 6-year-old South Indian Children - A crosssectional descriptive study. Oral Health \& Preventive Dentistry, 14, 267-273.

Hallett, K. B., \& O’Rourke, P. K. (2003). Social and behavioural determinants of early childhood caries. Australian Dental Journal, 48, 27-33.

Hassell, T. M., \& Harris, E. L. (1995). Genetic influences in caries and periodontal diseases. Critical Reviews in Oral Biology and Medicine, 6, 319-342.

Health and Family Welfare Department. (2013). Monthly bulletin on family welfare performance in Tamil Nadu. Retrieved from http://www.tnhealth.org/dfw/dfwpub.htm

Holzinger, K. J. (1929). The relative effect of nature and nurture influences on twin differences. Journal of Educational Psychology, 20, 241.

Izakovicova Holla, L., Borilova Linhartova, P., Lucanova, S., Kastovsky, J., Musilova, K., Bartosova, M., ... Dusek, L. (2015). GLUT2 and TAS1R2 polymorphisms and susceptibility to dental caries. Caries Research, 49, 417424.

Jackson, R. W., Snieder, H., Davis, H., \& Treiber, F. A. (2001). Determination of twin zygosity: A comparison of DNA with various questionnaire indices. Twin Research, 4, 1218.

Kalra, G., Bansal, K., \& Sultan, A. (2011). Prevalence of early childhood caries and assessment of its associated risk factors in preschool children of urban Gurgaon, Haryana. Indian Journal of Dental Sciences, 3, 12-16.

Kalsbeek, H., \& Verrips, G. H. (1994). Consumption of sweet snacks and caries experience of primary school children. Caries Research, 28, 477-483.

Kumarihamy, S. L., Subasinghe, L. D., Jayasekara, P., Kularatna, S. M., \& Palipana, P. D. (2011). The prevalence of early childhood caries in 1-2 yrs olds in a semi-urban area of Sri Lanka. BMC Research Notes, 4, 336.

Lee, S. H., Wray, N. R., Goddard, M. E., \& Visscher, P. M. (2011). Estimating missing heritability for disease from genome-wide association studies. American Journal of $\mathrm{Hu}$ man Genetics, 88, 294-305.

Liu, H., Deng, H., Cao, C. F., \& Ono, H. (1998). Genetic analysis of dental traits in 82 pairs of female-female twins. Chinese Journal of Dental Research, 1, 12-16.

Lovelina, F. D., Shastri, S. M., \& Kumar, P. D. (2012). Assessment of the oral health status of monozygotic and dizygotic twins - A comparative study. Oral Health \& Preventive Dentistry, 10, 135-139.

Lykken, D. T. (1978). The diagnosis of zygosity in twins. Behavior Genetics, 8, 437-473.
Mansbridge, J. N. (1959). Heredity and dental caries. Journal of Dental Research, 38, 337-347.

Milnes, A. R. (1996). Description and epidemiology of nursing caries. Journal of Public Health Dentistry, 56, 38-50.

Moimaz, S. A., Borges, H. C., Saliba, O., Garbin, C. A., \& Saliba, N. A. (2016). Early childhood caries: Epidemiology, severity and sociobehavioural determinants. Oral Health \& Preventive Dentistry, 14, 77-83.

Morrison, J., Laurie, C. C., Marazita, M. L., Sanders, A. E., Offenbacher, S., Salazar, C. R., ... Shaffer, J. R. (2016). Genome-wide association study of dental caries in the hispanic communities health study/study of Latinos (HCHS/SOL). Human Molecular Genetics, 25, 807816.

Ooi, G., Townsend, G., \& Seow, W. K. (2014). Bacterial colonization, enamel defects and dental caries in 4- to 6-yearold mono- and dizygotic twins. International Journal of Paediatric Dentistry, 24, 152-160.

Ooki, S., Yamada, K., \& Asaka, A. (1993). Zygosity diagnosis of twins by questionnaire for twins' mothers. Acta Geneticae Medicae et Gemellologiae, 42, 17-22.

Opal, S., Garg, S., Jain, J., \& Walia, I. (2015). Genetic factors affecting dental caries risk. Australian Dental Journal, 60, 2-11.

Paunio, P., Rautava, P., Sillanpaa, M., \& Kaleva, O. (1993). Dental health habits of 3-year-old Finnish children. Community Dentistry and Oral Epidemiology, 21, 4-7.

Peeters, H., Van Gestel, S., Vlietinck, R., Derom, C., \& Derom, R. (1998). Validation of a telephone zygosity questionnaire in twins of known zygosity. Behavior Genetics, 28, 159-163.

Prakash, P., Subramaniam, P., Durgesh, B. H., \& Konde, S. (2012). Prevalence of early childhood caries and associated risk factors in preschool children of urban Bangalore, India: A cross-sectional study. European Journal of Dentistry, 6, 141-152.

Price, T. S., Freeman, B., Craig, I., Petrill, S. A., Ebersole, L., \& Plomin, R. (2000). Infant zygosity can be assigned by parental report questionnaire data. Twin Research, 3, 129133.

Psoter, W. J., Pendrys, D. G., Morse, D. E., Zhang, H. P., \& Mayne, S. T. (2009). Caries patterns in the primary dentition: Cluster analysis of a sample of 5169 Arizona children 5-59 months of age. International Journal of Oral Science, 1 , 189-195.

Retnakumari, N., \& Cyriac, G. (2012). Childhood caries as influenced by maternal and child characteristics in pre-school children of Kerala - An epidemiological study. Contemporary Clinical Dentistry, 3, 2-8.

Shaffer, J. R., Wang, X., Desensi, R. S., Wendell, S., Weyant, R. J., Cuenco, K. T., ... Marazita, M. L. (2012). Genetic susceptibility to dental caries on pit and fissure and smooth surfaces. Caries Research, 46, 38-46.

Sharma, K. (1997). The twinning rates and epidemiological characteristics of births in southeast Uttar Pradesh, India. Acta Geneticae Medicae et Gemellologiae, 46, 47-56.

Shuler, C. F. (2001). Inherited risks for susceptibility to dental caries. Journal of Dental Education, 65, 1038-1045. 
Slater, E. (1963). Diagnosis of zygosity by finger prints. Acta Psychiatrica Scandinavica, 39, 78-84.

Spitz, E., Moutier, R., Reed, T., Busnel, M. C., Marchaland, C., Roubertoux, P. L., \& Carlier, M. (1996). Comparative diagnoses of twin zygosity by SSLP variant analysis, questionnaire, and dermatoglyphic analysis. Behavior Genetics, 26, 55-63.

Tinanoff, N. (1998). Introduction to the Early Childhood Caries Conference: Initial description and current understanding. Community Dentistry and Oral Epidemiology, 26, S5-S7.

Townsend, G. C., Aldred, M. J., \& Bartold, P. M. (1998). Genetic aspects of dental disorders. Australian Dental Journal, 43, 269-286.

Wang, X., Shaffer, J. R., Weyant, R. J., Cuenco, K. T., DeSensi, R. S., Crout, R., ... Marazita, M. L. (2010). Genes and their effects on dental caries may differ between primary and permanent dentitions. Caries Research, 44, 277-284.

Werneck, R. I., Mira, M. T., \& Trevilatto, P. C. (2010). A critical review: An overview of genetic influence on dental caries. Oral Diseases, 16, 613-623.

Wilson, R. S. (1980). Bloodtyping and twin zygosity: Reassessment and extension. Acta Geneticae Medicae et Gemellologiae, 29, 103-120.

Zeng, Z., Shaffer, J. R., Wang, X., Feingold, E., Weeks, D. E., Lee, M., ... Marazita, M. L. (2013). Genome-wide association studies of pit-and-fissure- and smooth-surface caries in permanent dentition. Journal of Dental Research, 92, 432437.

Zhang, M., Chen, Y., Xie, L., Li, Y., Jiang, H., \& Du, M. (2015). Pyrosequencing of plaque microflora in twin children with discordant caries phenotypes. PLoS One, 10, e0141310. 